\title{
Does Socioeconomic Inequality in Health Persist among Older People Living in Resource-Poor Urban Slums?
}

\author{
Jane C. Falkingham, Gloria Chepngeno-Langat, Catherine \\ Kyobutungi, Alex Ezeh, and Maria Evandrou
}

\begin{abstract}
Using self-reported health that assesses functionality or disability status, this paper investigates whether there are any differences in health status among older people living in a deprived area of Nairobi, Kenya. Data from a cross-sectional survey of 2,037 men and women aged 50 years and older are used to examine the association between socioeconomic position and self-reported health status across 6 health domains. Education, occupation, a wealth index, and main source of livelihood are used to assess the presence of a socioeconomic gradient in health. All the indicators showed the expected negative association with health across some, but not all, of the disability domains. Nonetheless, differences based on occupation, the most commonly used indicators to examine health inequalities, were not statistically significant. Primary level of education was a significant factor for women but not for men; conversely, wealth status was associated with lower disability for both men and women. Older people dependent on their own sources of livelihood were also less likely to report a disability. The results suggest the need for further research to identify an appropriate socioeconomic classification that is sensitive in identifying poverty and deprivation among older people living in slums.
\end{abstract}

KEYWORDS Health inequality, Older people, Urban slums, Socioeconomic position

\section{INTRODUCTION}

The gradient in the association between socioeconomic status and health where those with higher status live longer, enjoy better health, and experience less disability is well documented, particularly in developed societies against a backdrop of general advancement in medicine and improved health systems. ${ }^{1-3}$ Socioeconomic differences in health are present throughout most of the life course. Several studies have highlighted that differences persist, or even widen, in later life. The socioeconomic advantages and health experiences present during childhood, as well as in adulthood, cumulate and provide additional advantage to those with higher socioeconomic status in terms of, for instance, the onset of chronic diseases, and the severity of disease impairment on functionality. ${ }^{3,4}$ Conversely, some studies point to a narrowing in the gap in health inequalities at older ages due to the selective mortality and survival of healthier people and the beneficial effect of programs targeting older people. ${ }^{3,5}$

Falkingham, Chepngeno-Langat, and Evandrou are with the Centre for Research on Ageing, University of Southampton, Southampton, UK; Kyobutungi and Ezeh are with the African Population and Health Research Centre, Nairobi, Kenya.

Correspondence: Gloria Chepngeno-Langat, Centre for Research on Ageing, University of Southampton, Southampton, UK. (E-mail: tete@soton.ac.uk) 
Research in developing countries on socioeconomic differences in health is, however, very limited. Available evidence, gathered from a few studies, points to an inconsistent relationship between socioeconomic status and health outcomes. ${ }^{6-9}$ Similarly, the association between socioeconomic status and health risk behaviors is also inconsistent. ${ }^{10}$ Less studied is the health and well-being of older people in developing countries and how it is associated with socioeconomic status.

\section{Older People in Developing Countries}

The number of older people is growing rapidly, and currently, about two-thirds of the world's older people live in developing countries. ${ }^{11}$ There are large differences in the level and pace of aging between the regions of the developing world, with the proportion of older people in Africa $(5 \%)$ relatively modest compared with, for instance, Southeast Asia (8\%), South America (10\%), and Central America (11\%). Although the share of older people in Africa remains low, the growth in absolute terms raises concerns. Africa is currently estimated to have about 50 million older people aged 60 years and older, and the number is projected to increase dramatically by 2025. ${ }^{11}$ Coupled with this is the recognition that cities in sub-Saharan Africa are increasingly becoming home to a growing number of older people who are largely aging in situ, with few prospects of out-migrating to rural areas. ${ }^{12-14}$ Population aging in Africa is however taking place amid low levels of socioeconomic development. ${ }^{15}$

Older people in Africa are faced with a wide range of challenges that affect their economic and social well-being as well as their health. Furthermore, older people are often not a priority in health programs, which largely focus on infants, children, and women of reproductive age and, increasingly, on HIV/AIDS. ${ }^{16,17}$ Additionally, in Africa, pensions cover a very small minority of the older population; most pension schemes are contributory and occupation-based and thus accessible only to workers in the public and formal sectors. ${ }^{17,18}$ Nonetheless, a number of countries in Africa such as South Africa, Botswana, Lesotho, Namibia, Senegal, and Mauritius have introduced either a means-tested or nontested noncontributory social pension with universal access, ${ }^{18-20}$ despite the challenges of sustainability, ${ }^{17,21,22}$ administrative costs, and inclination to mismanagement or abuse. ${ }^{23,24}$ A lifetime of low economic status and poor access to healthcare nevertheless means that the majority of older people in Africa are entering old age in poverty and poor health. ${ }^{16}$ The diminishing capacity to engage in income generation, particularly in urban areas in terms of both physical capacity and relevant skills, also increases older people's risk to poor health and economic outcomes. ${ }^{16,17}$

Whereas older people in rural areas are generally poorer than their urban counterparts, ${ }^{18}$ and with poor access to health services, ${ }^{25}$ growing evidence highlights a disadvantaged urban population. A popular sense of filial obligation and material support for older people have declined rapidly in urban areas due to individualistic or nuclear-focused families as opposed to extended or multigenerational support, and also due to resource constraints among the younger adults expected to provide the support. ${ }^{26,27}$ In addition to this context, aging and poverty are expected to be key features of many cities in the developing world with major health disadvantages. ${ }^{28}$ Older people in urban areas living in informal settlements or slums and those engaged in the informal sector are likely to be among the worst off. Furthermore, older people are faced with a dual burden of infectious diseases and chronic and debilitating diseases that cause disability. ${ }^{29}$ Therefore, research on the determinants of health of older people in developing countries is a pertinent public health issue. This paper seeks firstly to understand whether socioeconomic differences in reporting a disability exist among older people living in resource-poor 
neighborhoods of Nairobi, Kenya and, secondly, to explore how these differentials vary according to the indicators of health and socioeconomic status used.

\section{DATA AND SETTING}

The study was nested within the Nairobi Urban Health Demographic Surveillance System (NUHDSS) which follows up the entire population of usual residents of 2 slum areas: Korogocho and Viwandani numbering approximately 60,000 individuals. Older people (50 years or older) comprise $5 \%$ of the total population, and almost two-thirds of the resident population are aged between 15 and 49 years, while children aged $0-14$ years make up an additional $30 \%$ of the population. The median age is 23 years, which is high compared with the national average of 18 years, and considering that almost half of the country's population is 15 or younger; this reflects the in-migration of young adults to the slums in search of work. The core function of the NUHDSS is to monitor population dynamics. Additionally, the NUHDSS acts as a platform for conducting other panel and crosssectional surveys within the defined geographical area. Hence, data for this study are part of a larger, 5-year nested research program, the Urbanization Poverty and Health Dynamics Program (UPHD), that seeks to understand the linkages among migration, poverty, and health consequences across different stages of the life course for residents of these 2 slums. One of the components of the research program, titled Survey on Social, Health, and Overall Wellbeing of Older People, sought to investigate the factors associated with the social, health, and economic status of older people.

All people 50 years and older $(2,612)$ who were resident in the NUHDSS during the surveillance round preceding the baseline survey were eligible for interview. Therefore, eligibility was determined by age and residence in the demographic surveillance area at the time of the recruitment. Participants were recruited into the study in 2 phases: the first cohort was recruited from October 2006-February 2007 and the second cohort recruited from October-December 2007. Whereas 60 years is conventionally used as the cutoff age for older people, especially in aging populations, ${ }^{11} 50$ years was selected in this study due to the low life expectancy in Kenya, which is estimated at 54 years for both men and women, ${ }^{15}$ and the low age of retirement, which is currently set at 55 years. ${ }^{30}$ Setting the minimum age for eligibility at 50 years therefore allowed a sufficient number of participants for the survey. The response rate for the survey was $79 \%$, and nonresponse was largely due to failure to establish contact. Postsurvey weights were developed to adjust for nonresponse based on the age, sex, and the level of education composition of the target population. Information on socioeconomic status comes from a study on detailed household livelihood and amenities conducted concurrently with the survey on older people, and all households with older people were eligible. A total of 2,037 older people were covered by both studies, hence the sample size used in this paper.

All the interviews were interviewer-administered and were conducted at the respondent's home after obtaining a verbal and/or written informed consent from the participant. The language used during the interview was Kiswahili, which is the lingua franca in the linguistically heterogeneous and cosmopolitan city. The study protocol and ethics were approved by the Kenya Medical Research Institute's (KEMRI) Ethical Review Committee, mandated by the Ministry of Health in Kenya to review research proposals involving human subjects. 


\section{Health Outcome Measures}

The study uses self-reported health to assess functionality. Physical functioning is an important measure of health and well-being, particularly among older people. Additionally, how an individual rates his/her functional status is known to be significantly associated with clinical indicators of well-being such as presence of chronic diseases and hospitalization, ${ }^{31}$ and even in predicting mortality. ${ }^{32,33}$ The health indicator used is the World Health Organization's (WHO) functionality and disability measure-the 12-item WHO Disability Assessment Schedule (WHODAS12) that assesses day-to-day functioning at the physical, personal, and social levels based on 6 different domains: cognition, mobility, self-care, interpersonal interactions, household activities, and participation in society. Cognition refers to the ability to concentrate or learn a new task. Mobility relates to walking, prolonged standing, and being able to stand up quickly from sitting down. Self-care refers to one's capacity to perform activities of daily living. These 3 domains-cognition, selfcare, and mobility - relate to physiological functioning. Interpersonal interaction measures difficulties with interacting with other people and dealing with conflicts or tensions. Household activities refer to duties relating to domestic activities and household chores. Interpersonal interactions and bousehold activities refer to personal level of functioning. Only one domain, participation in society, measures functioning at societal level as it refers to the individual having difficulty in joining or taking part in community activities. Combining different health domains is expected to yield a better representation of well-being than using fewer or singleitem indicators. ${ }^{34-36}$ The different domains may, however, vary on how sensitive they are across various individual characteristics. Therefore, any divergence in reporting across the various domains of well-being provides a better understanding of the indicators being observed and health disparity among the subgroups in the study population. . $^{37-39}$

The participants were asked to assess 12 functionality items on a 5-point Likert scale, with questions phrased in the manner "In the last 30 days, how much difficulty/problems did you have with...." A score for each of the domains was generated by recoding the 12 items with a weight of either 2 or 4 as the maximum possible score, which was then summed and converted to a percentage to allow comparison across domains. The resulting score therefore range from 0 to 100 , with higher scores indicating more functional impairment. The overall disability score is an aggregate of the 6 domains. This paper unpacks the composite score to assess if there are differences in the direction of effect of the individual components that make up the overall disability score by recognizing the multifaceted nature of disability. The composite score combines both physical and psychosocial dimensions of disability. Overall, all the domains are positively and strongly correlated with each other. Nonetheless, cognition and interpersonal interactions are the least correlated with the other domains and with the overall disability score, unlike mobility and self-care, which are highly correlated with the composite score.

\section{Socioeconomic Variables}

A range of indicators are used depicting the socioeconomic position of individuals and their effect on the 6 functionality domains and overall disability health measure. These indicators are education level, type of employment, the main source of livelihood, and wealth index. Education is significantly correlated with type of employment $\left(r^{2}=0.30, p<0.001\right)$ and main source of livelihood $\left(r^{2}=0.26, p<0.001\right)$. 
Similarly, the type of employment and main source of livelihood were also positively correlated $\left(r^{2}=0.28, p<0.001\right)$. The wealth grouping is however weakly correlated with the level of education $\left(r^{2}=0.02, p=0.277\right)$ and type of employment $\left(r^{2}=0.01, p=0.628\right)$ but not the main source of livelihood $\left(r^{2}=0.09 p=0.001\right)$. Even though these indicators are often related and sometimes used interchangeably to measure socioeconomic position, they may affect health outcomes variably as well as at different stages in the life course. ${ }^{40}$

Education reflects intellectual capacity to comprehend, access, and utilize health promotion messages and services, while it also determines the type of employment opportunities accessible to an individual. ${ }^{41}$ The variable on education used here refers to the highest education level attained and has been categorized into 3 dummy variables: primary, secondary or higher, and those never been to school taken as the reference category.

The type of employment activity is strongly associated with income and therefore access to material resources and expenditure that enhances health. Employment was categorized into 4 groups. The first employment category includes those who run their own businesses or individual enterprises such as people peddling wares in the streets and vegetable sellers. The informal employment category comprises mainly workers with temporary and irregular employment, for whom the primary mode of payment is a daily rate or piecemeal. The third category, formal employment, encompasses individuals with longer contracts and more regular payments relative to other employment categories, received on either a weekly or monthly basis. The fourth category, coded as other, includes mainly those engaged in urban farming along road reserves and other open spaces within the city, and those foraging for recyclable waste materials at garbage dumpsites. Older people engaged in the other category of employment were taken to be the reference group.

The wealth index is used as a proxy to capture the households' wealth status over a long period of time. It is also a reliable measure in predicting health. ${ }^{42,43}$ The index was computed using characteristics of housing and a set of utility household items accessible to or used by the individuals' household. The individuals were grouped into 3 approximately equal bands, namely lowest (reference group), middle, and highest wealth group.

Given the almost nonexistent pensions or institutional support in the study area, older people raise income for their livelihood from various sources. Therefore, the main source of livelihood for the older people was also included as an indicator to assess socioeconomic position. The group of older people whose main source of livelihood was from informal social or filial networks was taken as the reference category, the other categories being those who participate in a waged or self-employed occupation, and those who rely on income from savings or assets.

Variables included in the models as control variables were age, marital status, ethnicity, and living arrangements, which have been shown from previous studies to be highly correlated with health among older people. Functionality is inversely correlated with age, whereas being in a marital union has beneficial effect on health. ${ }^{44}$ Ethnicity has strong correlation with health particularly in studies conducted in developed countries. ${ }^{45-47}$ Age was included as a categorical variable taking the younger old (50-54 years) as the reference category. The living arrangement of the older person was assessed based on the number and age composition of people in the household. 


\section{Statistical Analyses}

Multiple linear (ordinary least squares-OLS) regression models are used to assess the association between socioeconomic status and self-reported disability. Due to the highly skewed distribution, logarithmic transformation of the WHODAS scores was performed to meet the assumptions of linear regression, and the coefficients and standard errors were back-transformed. The first step involved estimating regression models for each of the 4 socioeconomic indicators-education, type of employment, main sources of livelihood, and the wealth grouping-and the disability domains index, adjusted for covariates associated with health, namely age, gender, marital status, ethnicity, and living arrangements. In the second step, all the socioeconomic status indicators were added to the same model to determine the effect of each indicator, while controlling for the effect of the others as well as the control variables used in the first step. All the models are estimated separately for men and women. The level of statistical significance used was the $p$ value $\leq 0.05$.

\section{RESULTS}

\section{Characteristics of the Sample and Bivariate Analysis}

Table 1 presents the sociodemographic characteristics of the sample and the percentage distribution of the variables of interests for women and men. The mean age of the study participants was 58 years, with women significantly older (61 years) compared to men (57 years). The sample consisted largely of males $(65 \%)$. This high sex ratio is typical for most cities in Africa, including Nairobi, where males outnumber females when compared to rural areas or other cities in the world. ${ }^{48}$ These differences reflect the historical rural-urban migration patterns and gender variations that typically characterized earlier migrants to the city. The majority of the current older people in Nairobi migrated to the city during the preindependence period and immediately following independence, when there was a strong bias toward single male labor migrants. ${ }^{49,50}$ Although the proportion of women migrants has been on the increase, causing the sex ratio to gradually fall, men still outnumber women among migrants to urban areas. ${ }^{51,52}$

The dominant ethnic groups in the sample population (Kikuyu, Embu, and Meru), who originate from the central and eastern provinces of Kenya, make up almost half $(44 \%)$ followed by Kamba (16\%). The Luhya, Luo, and Somali/Borana ethnic groups each comprise a similar proportion out of the total population. The dominancy of the ethnic groups from the central and eastern provinces may be reflective of the composition of earlier migrants to the city, where communities from provinces in close proximity to Nairobi dominated. ${ }^{48,53}$ The ethnic distribution in these slums does not reflect the country's ethnic composition, nor is it representative of slums in Nairobi. ${ }^{54}$ Generally, most slums in Nairobi depict a unique spatial segregated pattern based on ethnicity, which can be accounted for by chain migration wherein the presence of kin and relatives provide a base for new migrants, thus encouraging migrants from a specific place of origin to settle predominantly in one area. 49

More than half of the older population reported primary schooling as their highest educational level (55\%), and 15\% had secondary education or higher. Older women tended to be less educated compared with men, with over half of the women having no education $(51 \%)$ compared with only $18 \%$ of men. Huge gender differences are also observed among those with secondary education or higher. 
TABLE 1 Demographic and socioeconomic characteristics of the study population compared across gender

\begin{tabular}{|c|c|c|c|}
\hline Sociodemographic and socioeconomic characteristics & Women & Men & Total \\
\hline \multicolumn{4}{|l|}{ 5-year age groups $* * *$} \\
\hline $50-54$ & 39.9 & 49.5 & 46.2 \\
\hline $55-59$ & 19.1 & 24.0 & 22.3 \\
\hline $60-64$ & 13.0 & 12.3 & 12.5 \\
\hline $65-69$ & 10.0 & 6.3 & 7.6 \\
\hline $70+$ & 18.0 & 8.0 & 11.5 \\
\hline Mean age & 60.6 & 57.3 & 58.4 \\
\hline \multicolumn{4}{|l|}{ Current marital status ${ }^{* * *}$} \\
\hline Married & 32.4 & 90.0 & 69.9 \\
\hline Divorced/separated & 18.5 & 3.8 & 9.0 \\
\hline Widowed & 40.6 & 5.2 & 17.6 \\
\hline Never married & 8.5 & 1.0 & 3.6 \\
\hline \multicolumn{4}{|l|}{ Ethnic group $* * *$} \\
\hline Kikuyu/Embu/Meru & 57.3 & 36.7 & 43.9 \\
\hline Luhya & 6.5 & 16.9 & 13.3 \\
\hline Luo & 7.1 & 15.1 & 12.3 \\
\hline Kamba & 13.1 & 16.9 & 15.6 \\
\hline Somali/Borana & 12.6 & 9.9 & 10.8 \\
\hline Other groups & 3.5 & 4.5 & 4.1 \\
\hline \multicolumn{4}{|l|}{ Household size ${ }^{* * *}$} \\
\hline 1 & 31.8 & 41.0 & 37.8 \\
\hline 2 & 19.5 & 18.6 & 18.9 \\
\hline $3-4$ & 25.8 & 15.7 & 19.2 \\
\hline $5+$ & 22.9 & 24.7 & 24.1 \\
\hline \multicolumn{4}{|l|}{ Highest education level*** } \\
\hline Never attended school & 51.0 & 18.2 & 29.7 \\
\hline Primary & 43.0 & 61.8 & 55.2 \\
\hline Secondary & 6.0 & 20.0 & 15.1 \\
\hline \multicolumn{4}{|l|}{ Type of current/most recent employment ${ }^{* * *}$} \\
\hline Unemployed & 11.7 & 1.2 & 4.9 \\
\hline Runs own business & 61.0 & 35.9 & 44.7 \\
\hline Informal employment & 12.1 & 36.2 & 27.8 \\
\hline Formal employment & 4.1 & 23.2 & 16.5 \\
\hline Other & 11.1 & 3.6 & 6.2 \\
\hline \multicolumn{4}{|l|}{ Main source of livelihood ${ }^{* * *}$} \\
\hline Own or spouse's work & 57.3 & 73.5 & 67.9 \\
\hline Own savings/investments & 18.1 & 20.5 & 19.6 \\
\hline Dependent on others & 24.7 & 6.0 & 12.5 \\
\hline \multicolumn{4}{|l|}{ Wealth group ${ }^{* * *}$} \\
\hline Lowest group & 33.3 & 33.5 & 33.4 \\
\hline Middle group & 39.9 & 28.7 & 32.7 \\
\hline Highest group & 26.8 & 37.8 & 33.9 \\
\hline Total & 100.0 & 100.0 & 100.0 \\
\hline$N$ & $712(34.9 \%)$ & $1,325(65.1 \%)$ & 2,037 \\
\hline
\end{tabular}

$x^{2}$ test for differences between women and men ${ }^{* * *} p<0.001 ;{ }^{* *} p<0.01 ;{ }^{*} p<0.05$ (significance levels) 
Unestablished individual or household business enterprises form the main type of employment for the majority of older people $(45 \%)$. These enterprises comprise mainly petty trading such as vending of vegetables, household wares, or secondhand clothing. Only a minority of older people $(17 \%)$ are in contractual employment with a higher proportion of men $(23 \%)$ engaged in this form of employment compared with only $4 \%$ of women. Nonetheless, most of the older people in the study rely on their own or spouse's income $(68 \%)$ as their main source of livelihood with a higher proportion of women relying on external support from children/ relatives $(25 \%)$ compared with men $(6 \%)$. Most of the older people live in single member households $(38 \%)$ with women more likely to live in larger households and to co-reside with children under the age of 15 years.

Tables 2 and 3 present the summary statistics (mean and median) for the 6 individual health domains as well as the overall disability score, compared across socioeconomic characteristics of the study participants for women and men, respectively. In general, both men and women reported the highest disability scores in the mobility domain, whereas the lowest scores were reported in the selfcare domain. A large proportion of individuals reported no disability with self-care and participation in society, as shown by median scores unlike the other 4 domains (cognition, mobility, interpersonal, and life activities). On average, women generally recorded higher mean scores in all the domains compared with the men.

Higher mean scores were reported by older people who were unemployed, and those dependent on others for their livelihood. Education was inversely related with disability scores among the men, where those with no education reported the highest scores, followed by men with primary education; those with secondary education or higher reported the least disability scores. However, the relationship between education and reporting a disability was not linear for women, as those with no education reported the highest scores, followed by women with secondary education or higher. With regards to wealth status, older people in the highest wealth grouping reported the least disability scores across almost all the domains. Among women, scores were similar across wealth groupings in the self-care domain, whereas the relationship between wealth grouping and disability score was not linear for men in the cognition and self-care domains.

\section{Results from Multiple Regression Analyses}

The fitted models for each of the socioeconomic indicators for the 6 domains and the overall score are presented in Tables 4 and 5 for women and men, respectively. Age, marital status, ethnicity, and living arrangement are included as control variables in all the models. Negative coefficients in the regression models reflect an inverse association between socioeconomic status and disability. The magnitude and level of significance vary across the socioeconomic indicators and also the 6 disability domains and overall score.

The association between level of education and disability presented mixed findings. Among women, having primary education is significantly associated with less disability for cognition, self-care, participation in society, and the overall score compared with having no education. Interestingly, having secondary education did not have a similar effect across the disability domains as those with secondary education or higher reported higher disability scores; nonetheless, they were not significantly different from those with no education. For men, however, there were 


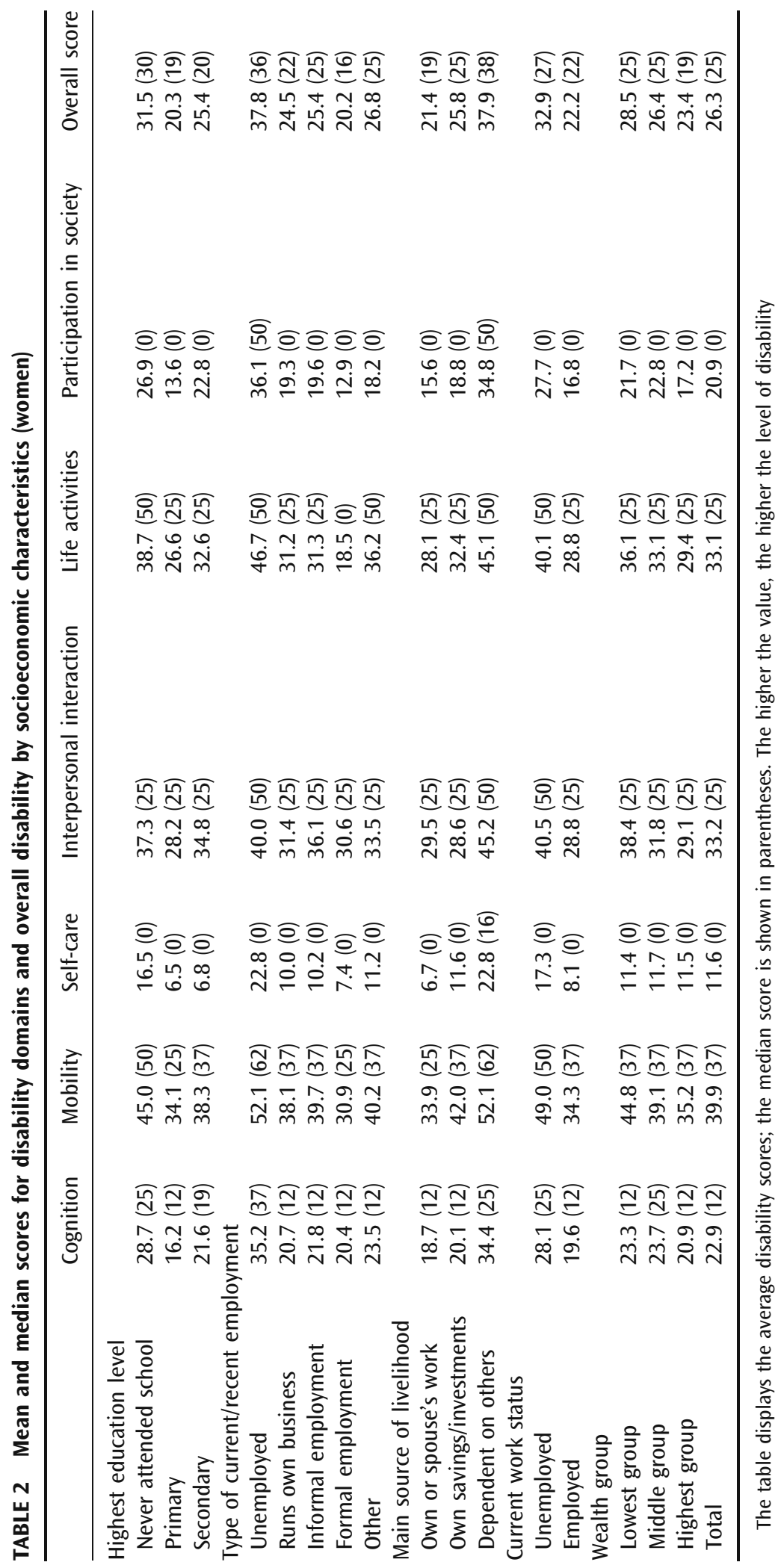




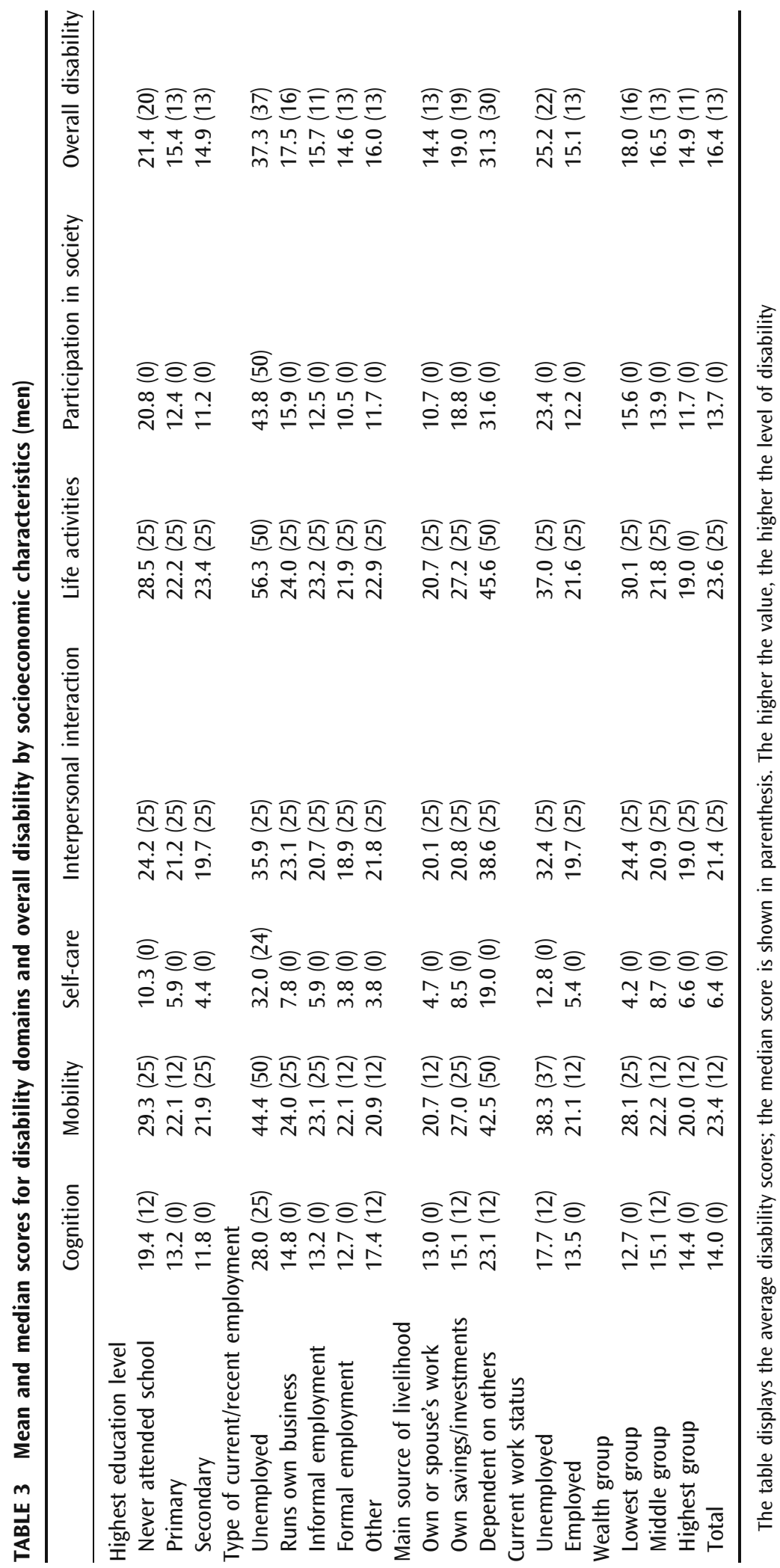




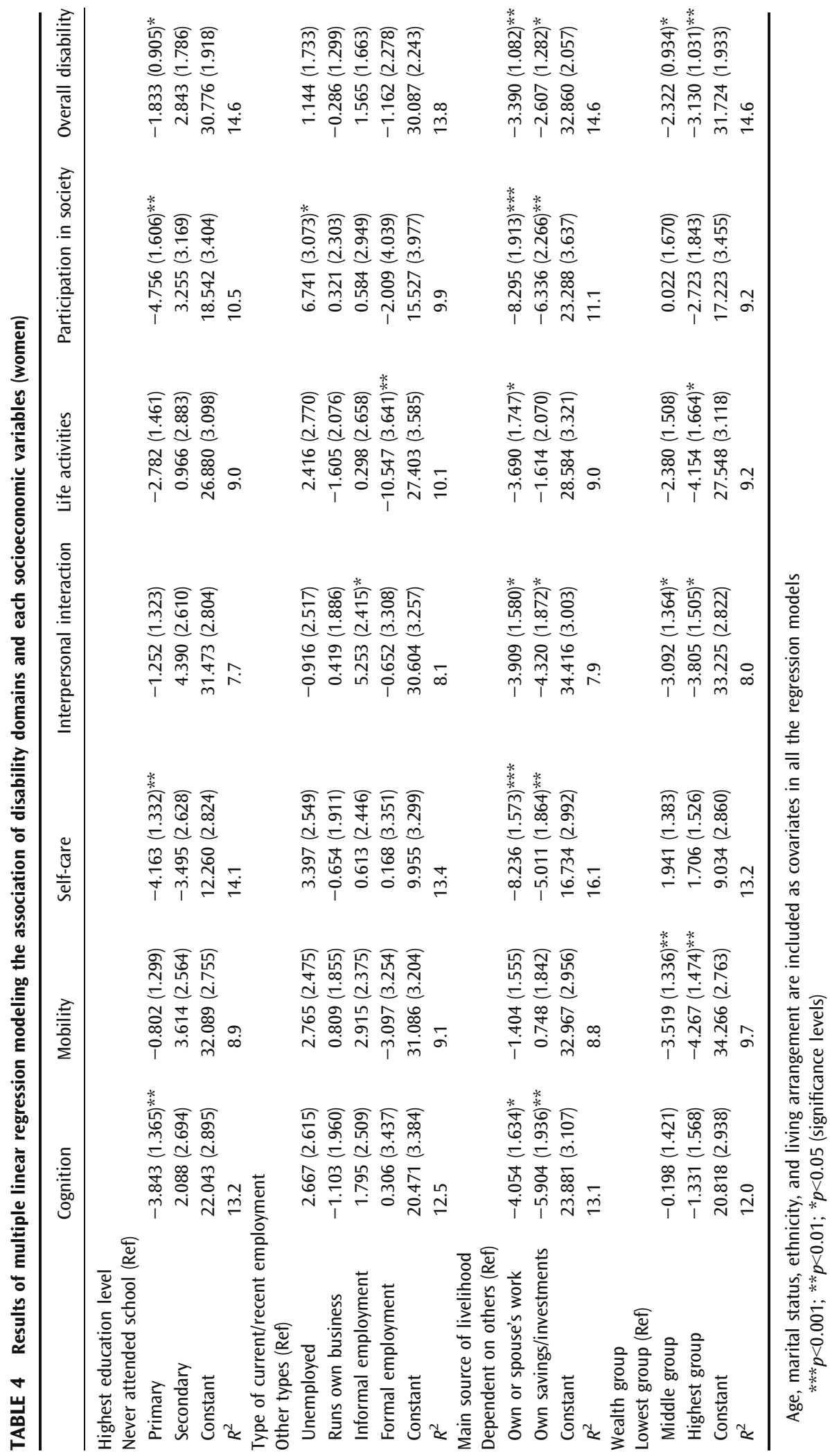




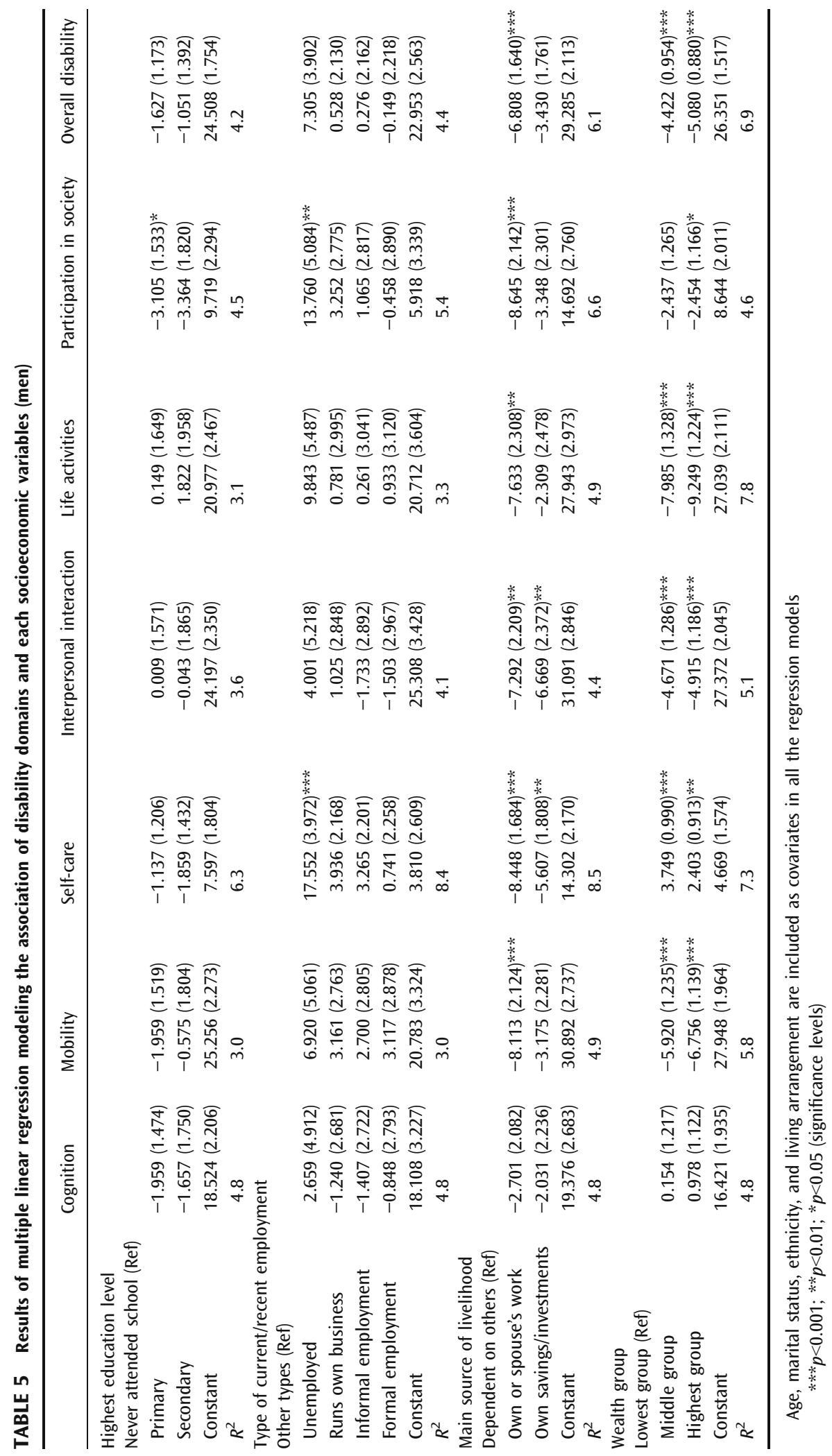


no statistically significant differences between having some level of education and the reference group (no education) after controlling for other factors, although having a higher education was inversely associated with disability across most of the domains.

The employment categories showed inconsistent association with disability across the different domains. For instance, whereas we might expect those in formal employment to be better off in terms of reporting less disability compared with those in the other category, this was not consistent across the disability domains. A significant difference was observed only in the life activities domain among the women, where those in formal employment were less likely to report disability compared with those in the category other. Men who were unemployed were significantly more likely to report higher disability scores in the self-care and participation in society domains compared with men in the other employment category (reference group).

Older people, both men and women, who rely on their own or their spouse's income as their main source of livelihood significantly reported less disability compared with those relying on their children/relatives. Older people depending on their investments or savings were also significantly more likely to report less disability compared with those relying on children/relatives for their main source of livelihood.

The wealth grouping showed the expected negative association with reporting a disability across most but not all the domains. Having higher wealth status was significantly associated with reporting less disability with the mobility, interpersonal interaction, and life activities domains, as well as, the overall disability domain among the women. Similarly for men, being in the middle or highest wealth group was associated with reporting less disability across all the domains except for cognition and self-care. Interestingly, being in a higher wealth grouping was associated with reporting disability with self-care for both men and women compared with the bottom grouping, and the differences were highly statistically significant among the men.

Tables 6 and 7 present the results of the combined regression models with all the 4 socioeconomic status indicators included in the model for women and men, respectively. Education remained significantly associated with reporting disability in the cognition, self-care, and participation in society among the women, whereas no significant effect was observed among the men across all the domains. The source of livelihood remained significant across all the domains in the aggregate models for both men and women, where older people relying on their own income for livelihood and those relying on personal savings were less likely to report a disability across almost all the 6 domains and the overall score compared with older people receiving external support. Wealth grouping was consistently associated with reporting a disability among the men and women.

\section{DISCUSSION}

The aim of this paper has been to assess socioeconomic differentials in selfreporting of health status by older people aged 50 years or older living in urban slums based on 6 separate functionality domains and a composite indicator measuring overall functionality. Higher socioeconomic position is known to have a direct effect on health through access to health services, better quality of care, and access to information that may lead to positive health behavior and 


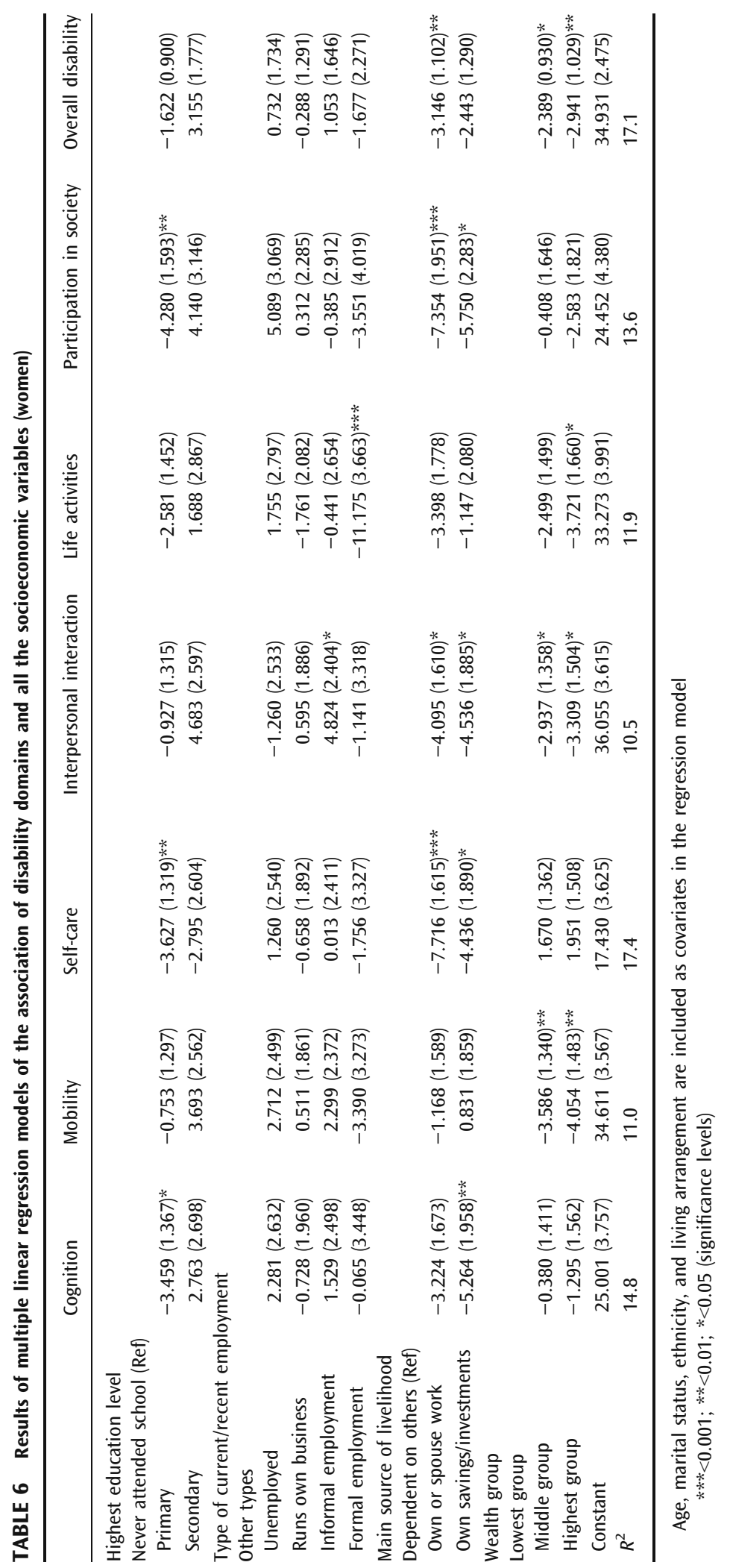




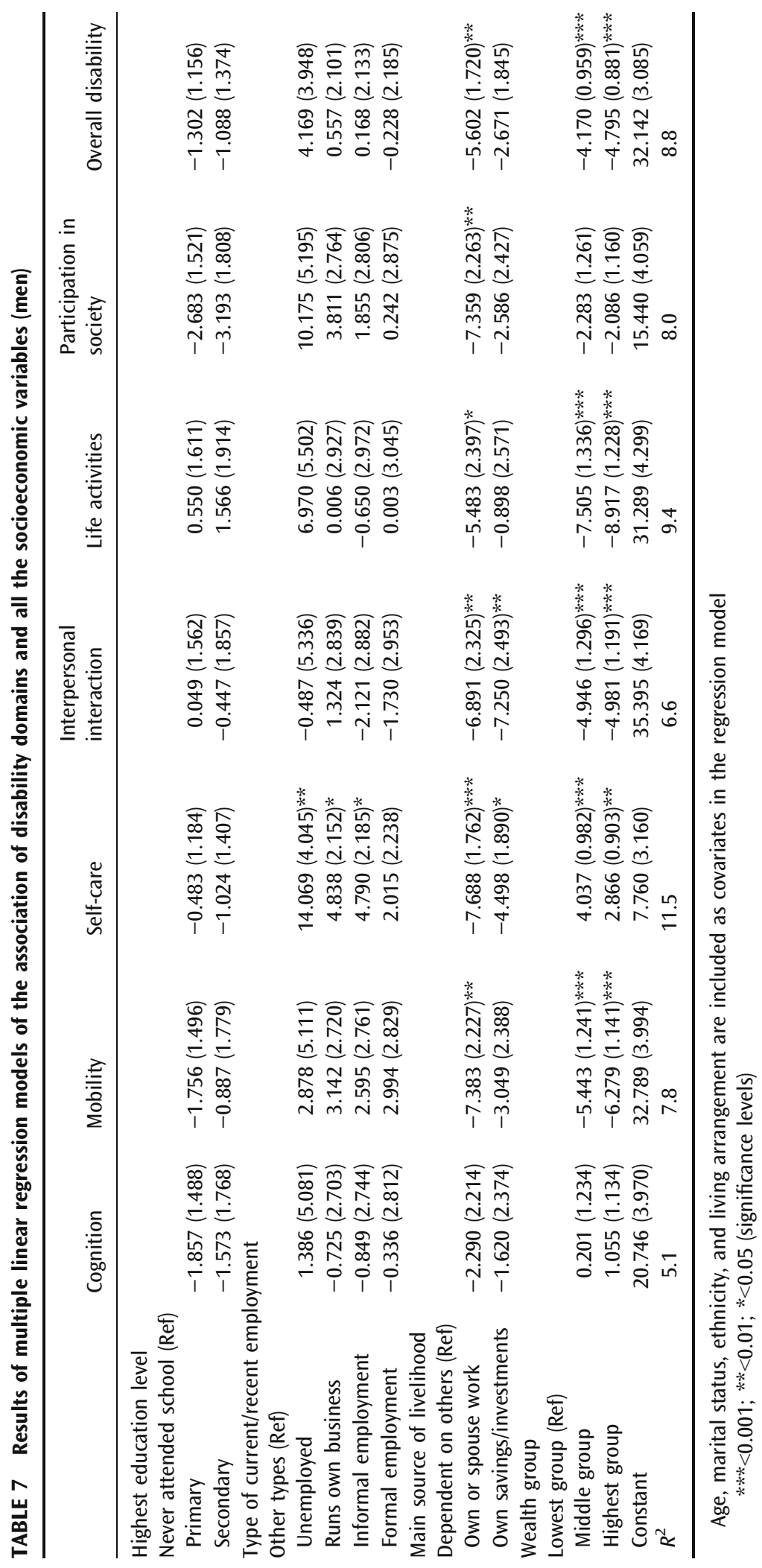


enhanced perception of one's own advantage relative to others of lower economic status. Four socioeconomic measures are used: education, type of employment, the wealth index, and main source of livelihood. We might expect insignificant variation in health outcome in a population that is overwhelmingly poor and in a context characterized by poor living conditions, high unemployment, and poor health outcomes.

The results highlight variation in the association of socioeconomic status and health based on the measure of socioeconomic indicator used and the specific functionality domain. The only socioeconomic indicator that emerged to be consistently sensitive to reporting functionality across all the functionality domains was source of livelihood. Older people relying mainly on their own or their spouse's income and those relying on savings or investment for their livelihood were more likely to report less disability compared with those largely dependent on others for their sustenance. The cross-sectional nature of the study means that the causal process through which the source of livelihood influences functional health status cannot be fully established. However, there are a number of plausible explanations. Older people relying on their own income and consequently having control over spending may have access to material resources that may enhance health. Having control over income also reduces vulnerability by enabling older people to cope with varied circumstances they may encounter, including seeking healthcare, which in the slum setting is largely accessed through private providers. ${ }^{55}$ Conversely, older people who are self-reliant economically may be highly selective in terms of their health as healthy status would enhance their employability. Therefore, older people who rely on external assistance as their main source of livelihood may do so because of a disability or poor health, and hence an inability to fend for themselves.

Contrasting differences were observed between older men and women with regard to the effect of educational attainment on reporting disability. The effect of having some level of education appeared to be stronger among women compared with men, even after controlling for the effect of other socioeconomic factors. The theoretical pathway through which education is known to influence health is acting as a means to income and other material resources, and also through behavioral effect, given that education influences receptiveness to health promotion messages, appreciation of health risk factors, and informed use of health services. The gender differences observed in this study may be explained in part by behavioral disparities between men and women in terms of, for instance, risky practices that result in poor health outcomes, the most notable being smoking and alcohol consumption, which are known to be more prevalent among men compared with women. 56,57

Occupation, the most commonly used socioeconomic indicator when assessing health inequalities, did not appear to be strongly associated with reporting a disability among the older people in this study. Occupation, which is closely related to income, is often seen as a problematic measure for older people who are no longer in formal employment. ${ }^{58}$ Nonetheless, a majority of the older people in the study are still actively participating in employment, most probably out of necessity rather than choice. The occupation categories used in this study may be largely similar in terms of income and thus not sensitive in differentiating this population based on disability as a health outcome. This highlights the methodological challenge relating to the measurement of health inequality among older people, and similarly the limited appropriateness of conventional socio- 
economic indicators for older people living in urban slums. The mixed direction of effect on the same socioeconomic status variable across the different disability domains raises caution on the use of single aggregate measures if the constituent components present divergent effects.

This study is not without limitations. The cross-sectional nature of the data does not allow for causal inference. The health indicators used are self-reported, hence subjective, and consequently not free from bias. The variation observed among population subgroups may be reflective of variations in true health status or it may be due to variation in how individuals evaluate their health. Any systematic differences in the understanding and use of response scales, as well as different expectations or variations in perception of what is considered as optimal health due to the effect of personal characteristics and social or cultural context may be reflected in differences in reported health across populations. In addition, having the same level of true health may not essentially result in similar self-reported health. Different subgroups of a population may use different cutoff points or reference levels, with the result that there is no "true-zero" used by all individuals in a survey. For instance, a number of studies have noted this weakness of self-rated health on how different socioeconomic groups rate their health ${ }^{59}$ and subsequent link with mortality. ${ }^{60,61}$ Another limitation is that health status observed in individuals during old age is a result of social and biological factors that evolve over the life course, and hence not fully appreciated in the cross-sectional nature of the study. Similarly, the socioeconomic position observed at only one point in time may not adequately explain the contribution of socioeconomic factors to health status.

\section{CONCLUSION}

Large inequalities, particularly in health and economic status, are common characteristics of developing countries. This is reflected particularly in access to healthcare and social services, and health outcomes including disease burden and consequent mortality. The need to reduce inequality in health remains a major health concern, and the factors associated with poor health outcomes among subgroups of the population, and which are amendable through public health intervention, remain a priority. This study therefore underscores the importance of studying disparities in health status even in a seemingly homogeneous and deprived slum setting. The findings draw attention to the need for appropriate classification of older people based on socioeconomic measures that allow for identification of a gradient in health.

\section{REFERENCES}

1. Blane D. Commentary: socioeconomic health differentials. Int J Epidemiol. 2001; 30(2): 292-3.

2. Braveman PA, Cubbin C, Egerter S, et al. Socioeconomic status in health research: one size does not fit all. JAMA. 2005; 294(22): 2879-88.

3. Demakakos P, Nazroo J, Breeze E, Marmot M. Socioeconomic status and health: the role of subjective social status. Soc Sci Med. 2008; 67(2): 330-40.

4. Sacker A, Head J, Bartley M. Impact of coronary heart disease on health functioning in an aging population: are there differences according to socioeconomic position? Psychosom Med. 2008; 70(2): 133-40.

5. Kim J, Durden E. Socioeconomic status and age trajectories of health. Soc Sci Med. 2007; 65(12): 2489-502. 
6. Liang J, Liu X, Gu S. Transitions in functional status among older people in Wuhan, China: socioeconomic differentials. J Clin Epidemiol. 2001; 54(11): 1126-38.

7. Park BH, Jung M, Lee TJ. Associations of income and wealth with health status in the Korean elderly. J Prev Med Public Health. 2009; 42(5): 275-82.

8. Zimmer Z, Chayovan N, Lin HS, Natividad J. How indicators of socioeconomic status relate to physical functioning of older adults in three Asian societies. Res Aging. 2004; 26 (2): 224-58.

9. Zimmer Z. Poverty, wealth inequality and health among older adults in rural Cambodia. Soc Sci Med. 2008; 66(1): 57-71.

10. Smith KV, Goldman N. Socioeconomic differences in health among older adults in Mexico. Soc Sci Med. 2007; 65(7): 1372-85.

11. United Nations. World Population Ageing, 2007. New York, NY: United Nations; 2007.

12. Chepngeno G, Ezeh AC. Between a rock and a hard place: perception of older people living in Nairobi city on return-migration to rural areas. Global Ageing. 2007; 4(3): 67-78.

13. Potts D. Shall we go home? Increasing urban poverty in African cities and migration processes. Geog. Jol. 1995;161

14. Potts D. The slowing of sub-Saharan Africa's urbanization: evidence and implications for urban livelihoods. Environ Urban. 2009; 21(1): 253-9.

15. Velkoff VA, Kowal PR. Population Aging in Sub-Saharan Africa: demographic dimensions 2006. Washington, DC: U.S. Census Bureau; 2007. P95/07-1.

16. Heslop A, Gorman M. Chronic poverty and older people in the developing world. Manchester, UK: Chronic Poverty Research Centre; 2002. Working paper no. 10.

17. Lloyd-Sherlock P. Old age and poverty in developing countries: new policy challenges. World Devel. 2000; 28(12): 2157-68.

18. Kakwani N, Subbarao K. Ageing and Poverty in Africa and the Role of Social Pensions. Brasília, Brazil: United Nations Development Programme, International Poverty Centre; 2005.

19. Holzman R, Hinz R. Old-Age Income Support in the 21st Century: an International Perspective on Pension Systems and Reform. Washington, DC: The World Bank; 2005.

20. Shen C, Williamson JB. Does a universal non-contributory pension scheme make sense for rural China? Jol Comp Soc Welfare. 2006; 22(2): 143-53.

21. Lloyd-Sherlock P. Formal social protection for older people in developing countries: three different approaches. J Soc Policy. 2002; 31(4): 695-713.

22. Lloyd-Sherlock P. Social policy and population ageing: challenges for north and south. Int J Epidemiol. 2002; 31(4): 754-7.

23. Kildal N, Kuhnle S. Old age pensions, poverty and dignity: historical arguments for universal pensions. Global Social Policy. 2008; 8(2): 208-37.

24. Willmore L. Universal pensions for developing countries. World Devel. 2007; 35(1): 24-51.

25. Darkwa OK, Mazibuko FNM. Population aging and its impact on elderly welfare in Africa. Int Jol Aging Human Dev. 2002; 54(2): 107-23.

26. Aboderin I. Decline in material family support for older people in Urban Ghana, Africa: understanding processes and causes of change. J Gerontol B Psychol Sci Soc Sci. 2004; 59 (3): S128-37.

27. Nana A, Gricco M. Urbanization, caring for elderly people and the changing African family: the challenge to social policy. Int Social Sec Rev. 1994; 47(3-4): 111-22.

28. Campbell T, Campbell A. Emerging disease burdens and the poor in cities of the developing world. J Urban Health. 2007; 84(1): 54-64.

29. Lloyd-Sherlock P. Population ageing in developed and developing regions: implications for health policy. Soc Sci Med. 2000; 51(6): 887-95.

30. Kenya National Bureau of Statistics. Kenya Facts and Figures 2007. Nairobi Government Press; 2007.

31. Myint PK, Luben RN, Surtees PG, et al. Relation between self-reported physical functional health and chronic disease mortality in men and women in the European 
prospective investigation into cancer (EPIC-Norfolk): a prospective population study. Ann Epidemiol. 2006; 16(6): 492-500.

32. Jurges H. Self-assessed health, reference levels and mortality. Appl Econ. 2008; 40(5): 569-82.

33. Jylha M. What is self-rated health and why does it predict mortality? Towards a unified conceptual model. Soc Sci Med. 2009; 69(3): 307-16.

34. Gardner DG, Cummings LL, Dunham RB, Pierce JL. Single-item versus multiple-item measurement scales: an empirical comparison. Educ Psy Measur. 1998; 58(6): 898-915.

35. Loo R. A caveat on using single-item versus multiple-item scales. J Manage Psychol. 2002; 17: 68-75.

36. Sloan JA, Aaronson N, Cappelleri JC, Fairclough DL, Varricchio C. Assessing the clinical significance of single items relative to summated scores. Mayo Clin Proc. 2002; 77(5): 479-87.

37. Diener E. Assessing subjective well-being: progress and opportunities. Soc Indic Res. 1994; 31(2): 103-57.

38. Shmueli A. Socio-economic and demographic variation in health and in its measures: the issue of reporting heterogeneity. Soc Sci Med. 2003; 57(1): 125-34.

39. Wiggins R, Netuveli G, Hyde M, Higgs P, Blane D. The evaluation of a self-enumerated scale of quality of life (CASP-19) in the context of research on ageing: a combination of exploratory and confirmatory approaches. Soc Indic Res. 2008; 89(1): 61-77.

40. Regidor E. Social determinants of health: a veil that hides socioeconomic position and its relation with health. J Epidemiol Community Health. 2006; 60(10): 896-901.

41. Galobardes B, Shaw M, Lawlor DA, Lynch JW, Davey SG. Indicators of socioeconomic position (part 1). J Epidemiol Community Health. 2006; 60(1): 7-12.

42. Filmer D, Pritchett LH. Estimating wealth effects without expenditure data-or tears: an application to educational enrolments in states of India. Demography. 2001; 38(1): 115-32.

43. Montgomery MR, Gragnolati M, Burke KA, Paredes E. Measuring living standards with proxy variables. Demography. 2000; 37(2): 155-74.

44. Robles TF, Kiecolt-Glaser JK. The physiology of marriage: pathways to health. Physiol Behav. 2003; 79(3): 409-16.

45. Heller PL, Briones DF, Schiffer RB, et al. Mexican-American ethnicity and cognitive function: findings from an elderly southwestern sample. J Neuropsychiatry Clin Neurosci. 2006; 18(3): 350-5.

46. Karlamangla AS, Miller-Martinez D, Aneshensel CS, Seeman TE, Wight RG, Chodosh J. Trajectories of cognitive function in late life in the United States: demographic and socioeconomic predictors. Am J Epidemiol. 2009; 170(3): 331-42.

47. Silveira ER, Ebrahim S. A comparison of mental health among minority ethnic elders and whites in East and North London. Age Ageing. 1998; 27(3): 375-83.

48. O'Connor AM. The African City. London: Hutchinson; 1983.

49. Byerlee D. Rural-urban migration in Africa: theory, policy and research implications. Int Migr Rev. 1974; 8(4): 543-66.

50. Gugler J. Women stay on the farm no more: changing patterns of rural-urban migration in Sub-Saharan Africa. JMAS. 1986; 27(2): 347-52.

51. Gould WTS, Oucho JO. Internal Migration, Urbanisation and Population Distribution. Chapter 7 Demographic Change in Sub-Saharan Africa. Washington, DC: National Academies Press; 1993: 256-96.

52. Beguy D, Bocquier P, Zulu EM. Circular migration patterns and determinants in Nairobi slum settlements. Demographic Research. 2010; 23(20): 549-86.

53. Obudho RO. Nairobi: national capital and regional hub. Chapter 9. In: Rakodi C, ed. The Urban Challenge in Africa: growth and Management of Its Large Cities. Tokyo/New York/Paris: United Nations University Press; 1997.

54. APHRC. Population and Health Dynamics in Nairobi's Informal Settlements: report of the Nairobi Cross-Sectional Slum Survey (NCSS) 2000. Nairobi, Kenya: Regal Press; 2002. 
55. Garner P, Thaver I. Urban slums and primary health care. BMJ. 1993; 306(6879): 667-8.

56. Denton M, Walters V. Gender differences in structural and behavioral determinants of health: an analysis of the social production of health. Soc Sci Med. 1999; 48(9): 1221-35.

57. Sulander T, Helakorpi S, Rahkonen O, Nissinen A, Uutela A. Smoking and alcohol consumption among the elderly: trends and associations, 1985-2001. Prev Med. 2004; 39 (2): 413-8.

58. Grundy E, Holt G. The socioeconomic status of older adults: how should we measure it in studies of health inequalities? J Epidemiol Community Health. 2001; 55(12): 895-904.

59. Cockerham WC, Sharp K, Wilcox JA. Aging and perceived health status. J Gerontol. 1983; 38(3): 349-55.

60. Singh-Manoux A, Dugravot A, Shipley MJ, et al. The association between self-rated health and mortality in different socioeconomic groups in the GAZEL cohort study. Int J Epidemiol. 2007; 36(6): 1222-8.

61. Dowd JB, Zajacova A. Does the predictive power of self-rated health for subsequent mortality risk vary by socioeconomic status in the US? Int J Epidemiol. 2007; 36(6): 1214-21. 